\title{
Anemia Ferropriva e Anemia de Doença Crônica: Distúrbios do Metabolismo de Ferro
}

\author{
Miriam Corrêa de Carvalho ${ }^{1}$, Emílio Carlos Elias Baracat ${ }^{2}$, Valdemiro Carlos Sgarbieri ${ }^{3}$
}

\begin{abstract}
A anemia ferropriva e a anemia de doença crônica correspondem às anemias mais comuns por distúrbios do metabolismo de ferro. A anemia ferropriva, desordem nutricional mais prevalente em todo o mundo, acomete principalmente crianças menores de cinco anos e mulheres em idade fértil. Os sinais clínicos da deficiência de ferro não são facilmente identificáveis e, muitas vezes, a anemia não é diagnosticada. Estes sinais incluem palidez, anorexia, apatia, irritabilidade, diminuição da atenção e deficiências psicomotoras. A anemia de doença crônica está presente em processos inflamatórios, infecciosos ou neoplásicos. Alguns autores entendem que, em lugar de considerar a anemia como uma anormalidade em doenças crônicas com quadro de infecção/inflamação, esta possa ser considerada como um mecanismo de defesa, não específico, em resposta do hospedeiro à invasão microbiana. A noção de que a deficiência de ferro representa um fator de proteção contra a infecção é baseada em estudos que demonstram a necessidade de ferro para o crescimento bacteriano e produção de toxinas.
\end{abstract}

Palavras-chave: anemia ferropriva, anemia da doença crônica, ferro

\section{Iron Deficiency Anemia and Chronic Disease Anemia. Iron Metabolic Disturbances}

Iron deficiency anemia and chronic disease anemia are the two most common diseases resulting from iron metabolic disturbances. Iron deficiency anemia is universally distributed. The most affected population groups are children between four months and five years of age, as well as reproductive-age women. The clinical signs of anemia are not easily recognizable, and many times go unnoticed. These signs include paleness, anorexia, apathy, irritability, reduced attention span and psychomotor deficiencies. The anemia of chronic disease is found in inflammatory, infection or neoplasic processes. Some authors have proposed that, instead of considering anemia in infections and chronic diseases a disorder associated with infection/inflammation, such anemia could be a nonspecific immunological defense mechanism, considered as the host's response to a microbiological invasion. The idea that iron deficiency can be a protective factor against infections is based upon studies that have shown that iron is necessary for the growth and production of bacterial toxins.

Keywords: Iron deficiency anemia, chronic disease anemia, iron

\footnotetext{
${ }^{1}$ Núcleo de Estudos e Pesquisas em Alimentação (UNICAMP)

${ }^{2}$ Departamento de Pediatria da Faculdade de Ciências Médicas (UNICAMP)

${ }^{3}$ Faculdade de Engenharia de Alimentos (UNICAMP)
} 


\section{Introdução}

A etiologia das anemias caracteriza-se pela biosíntese anormal de hemoglobina. As hemácias em desenvolvimento requerem ferro, protoporfirina e globina em quantidades ótimas para a produção de hemoglobina. Neste sentido, as anemias caracterizadas pela síntese deficiente de hemoglobina podem ser divididas em três grupos, dependendo de qual dos três compostos está deficiente. No grupo das anemias caracterizadas por distúrbios do metabolismo de ferro, podemos classificar a anemia ferropriva e a anemia de doença crônica como sendo as mais comuns ${ }^{1,2}$.

A anemia por deficiência de ferro é, isoladamente, a mais comum das deficiências nutricionais do mundo e ocorre como resultado de perda sanguínea crônica, perdas urinárias, ingestão e/ou absorção deficiente e aumento do volume sanguíneo. $\mathrm{Na}$ anemia ferropriva ocorre diminuição dos níveis plasmáticos de ferro. Os locais de reserva de ferro dos macrófagos estão depletados e, portanto, não podem fornecê-lo para o plasma. Conseqüentemente, a concentração plasmática de ferro cai a níveis que limitam a eritropoese. Os grupos mais vulneráveis para o desenvolvimento da anemia ferropriva são lactentes, crianças menores de 5 anos e mulheres em idade fértil ${ }^{1}$.

Freqüentemente, as doenças infecciosas, inflamatórias, traumáticas ou neoplásicas, que persistem por mais de um ou dois meses, são acompanhadas por uma anemia leve a moderada, denominada muitas vezes como anemia da inflamação ou infecção ou ainda como anemia de doença crônica. Como tais doenças são numerosas, este tipo de anemia é muito comum e sua incidência total é superada apenas pela anemia ferropriva, sendo mais prevalente entre indivíduos idosos ${ }^{3}$.

$\mathrm{Na}$ anemia de doença crônica, ocorre também diminuição dos níveis plasmáticos de ferro. Entretanto, apesar do nível de ferro dos macrófagos ser considerado normal ou aumentado, o fluxo ao plasma parece estar parcialmente bloqueado. Deste modo, o ferro acumula-se no macrófago, enquanto o nível plasmático cai e a medula está privada de suprimentos adequados ${ }^{1}$.

\section{Fisiologia e Metabolismo do Ferro}

O ferro caracteriza-se por ser um metal de transição e a extensão de sua utilização biológica está na capacidade de existir em diferentes estados de oxidação, formar muitos complexos, além de agir como um centro catalítico para diversas funções metabólicas. Presente na hemoglobina, este mineral é de fundamental importância para o transporte de oxigênio e dióxido de carbono, essenciais à respiração celular aeróbica, além de participar de componentes de numerosas enzimas celulares, importantes para o funcionamento do sistema imunológico, assim como dos citocromos que são indispensáveis para a produção de energia, de enzimas no ciclo do ácido cítrico, ribonucleotídeo redutase e NADPH redutase e, ainda, na síntese de dopamina, serotonina, catecolaminas e, possivelmente, do ácido gamaaminobutírico e na formação de mielina ${ }^{4,5}$.

Em condições normais, quando não ocorrem perdas sanguíneas ou processo de gestação, a quantidade de ferro presente no organismo é altamente preservada, sendo que apenas uma pequena quantidade a cada dia é perdida ${ }^{6}$. Aproximadamente $40 \mathrm{mg}$ de ferro por dia são necessários para a utilização interna do organismo humano, principalmente para substituição da hemoglobina. Expressiva parte desta quantidade é proveniente da reciclagem dos suplementos de ferro existentes no próprio organismo. A reciclagem fisiológica é tão eficiente que apenas 1 a 1,5mg de ferro, proveniente da absorção intestinal, é necessário para manter o balanço interno ${ }^{4}$.

As quantidades médias necessárias diariamente para os homens adultos e para as mulheres em idade fértil são cerca de $1,0 \mathrm{mg}$ e $1,5 \mathrm{mg}$ de ferro, respectivamente. $\mathrm{Na}$ gestação, principalmente no segundo e terceiro trimestres, para se preservar o balanço de ferro, são necessários 4 a $5 \mathrm{mg}$ de ferro, diariamente. Na infância, particularmente em períodos de rápido crescimento (6 a 24 meses), e na adolescência, as necessidades de ferro são também elevadas. As necessidades diárias de ferro para crianças, adolescentes masculinos e adolescentes femininos são $1,0 \mathrm{mg}, 1,2 \mathrm{mg}$ e $1,5 \mathrm{mg}$, respectivamente ${ }^{4,6}$. 
No organismo do homem adulto saudável existem de 4 a $5 \mathrm{~g}$ de ferro. Desta quantidade, 60 a $70 \%$ são classificados como essencial ou funcional e 30 a $40 \%$ como reserva ou não-essencial. O ferro essencial está incorporado à hemoglobina, mioglobina e certas enzimas respiratórias (citocromos), que catalisam os processos de oxidação-redução dentro da célula. $O$ ferro nãoessencial pode ser encontrado nos estoques de ferro do organismo, como a ferritina e a hemossiderina, além da transferrina ${ }^{7}$.

$\mathrm{Na}$ dieta, o ferro pode ser encontrado em duas formas: orgânica ou ferro hematínico e inorgânica ou ferro não-hematínico. O ferro hematínico é encontrado na hemoglobina e mioglobina, proveniente das carnes em geral, aves e peixes. O ferro não-hematínico está presente fundamentalmente nos alimentos vegetais, nos cereais e em outros alimentos, como composto férrico e ferroso ${ }^{6,8,9}$. Os mecanismos de absorção e a biodisponibilidade das duas formas de ferro, hematínico e não-hematínico, diferem-se marcadamente.

Detalhes precisos quanto aos mecanismos específicos da absorção intestinal de ferro, tanto seus mecanismos bioquímicos como sua regulação, não são totalmente conhecidos. Entretanto, a absorção de ferro consiste de sua captação pelas células da mucosa, de seu movimento através da célula e, finalmente, de sua liberação pela célula, para que possa atingir a circulação8.

O ferro hematínico, altamente biodisponível e pouco afetado por fatores dietéticos, é absorvido de forma distinta à do ferro não-hematínico, como complexo de porfirina-heme intacto pelas células da mucosa intestinal. A porção heme, após ser liberada da globina no lúmem intestinal, é absorvida. $\mathrm{Na}$ célula da mucosa, o radical heme sofre degradação enzimática pela ação da heme-oxigenase e o ferro é liberado ${ }^{10}$.

O ferro não-hematínico é insolúvel em água e tem a absorção afetada pela composição da dieta, além de outros fatores ${ }^{4,9}$. Presente nos alimentos, principalmente na forma férrica, após a digestão, pela ação do ácido clorídrico contido no suco gástrico, este tipo de ferro é reduzido a uma forma ferrosa, mais facilmente absorvida. Apesar de ambas as formas serem solúveis no $\mathrm{pH}$ ácido do estômago, apenas o ferro ferroso permanece solúvel no duodeno ${ }^{10}$. A absorção do ferro não-hematínico pode ser aumentada por substâncias, como o ácido ascórbico, que formam quelantes de ferro de baixo peso molecular ${ }^{5}$, assim como as proteínas, a frutose e o citrato, que formam complexos solúveis com o ferro, facilmente absorvidos ${ }^{10}$. Por outro lado, a absorção do ferro não-hematínico pode ser diminuída por alguns componentes da dieta como os fosfatos, taninos, polifenóis e oxalatos, por formarem complexos insolúveis com o ferro, afetando assim sua biodisponibilidade ${ }^{10}$.

No estômago, tanto o ferro hematínico quanto o ferro não-hematínico são liberados do alimento e rapidamente formam complexos de ferro, solúveis e insolúveis. No intestino, os complexos de ferro solúveis são captados pela membrana da borda em escova. Após a absorção, dependendo do estado nutricional de ferro do organismo, este pode ser armazenado como ferritina no citosol da célula intestinal, podendo retornar ao lúmem intestinal pela descamação natural das células da mucosa, ocorrendo em um período que pode envolver de dois a quatro dias ou ser rapidamente transportado através da célula e entrar no fluído intracelular e no plasma ${ }^{5,10}$.

A absorção de ferro é afetada, de forma significativa, pela mucosa intestinal, pela quantidade e natureza química do ferro ingerido nos alimentos, por alimentos presentes na dieta e uma variedade de outros fatores, como o estado nutricional de ferro do organismo e a taxa de produção de células vermelhas sanguíneas, que podem aumentar ou diminuir sua biodisponibilidade. Quando os níveis de ferro absorvidos pela dieta são adequados, a mucosa intestinal regulariza a sua absorção para manter constante o conteúdo de ferro do organismo. Desta forma, apenas valores entre 5 e $10 \%$ do ferro ingerido são absorvidos diariamente. Na deficiência de ferro, sua absorção pode aumentar de 10 a $20 \%$ ou até $30 \%{ }^{3,6}$ e, se as reservas de ferro no organismo estiverem reduzidas ou caso a eritropoese seja acelerada, sua absorção pode variar de 25 a $50 \%{ }^{2}$.

A deficiência de ferro pode ocorrer como 
resultado do balanço negativo prolongado de ferro ou devido à falha do organismo em atender às necessidades fisiológicas aumentadas. Em muitos casos, fatores etiológicos múltiplos estão envolvidos no desenvolvimento da deficiência.

O balanço negativo de ferro pode ocorrer em condições de baixo consumo de ferro biodisponível, de prejuízo na absorção (acloridria, cirurgia gástrica, doença celíaca e pica) e de aumento nas perdas de ferro pelo organismo (sangramento gastrintestinal, fluxo menstrual excessivo, doação de sangue, hemoglobinúria, sangramento auto-induzido, hemosiderose pulmonar idiopática, telangiectasia hemorrágica hereditária, distúrbio de hemostasia, insuficiência renal crônica, hemodiálise e anemia do corredor). As necessidades fisiológicas aumentadas correspondem à infância, gravidez e lactação, pois caracterizam-se por estados fisiológicos que apresentam necessidades aumentadas de ferro. Sendo assim, os grupos mais vulneráveis ao desenvolvimento da deficiência de ferro são os lactentes, crianças menores de 5 anos, gestantes e mulheres em idade fértil ${ }^{1,7}$.

A deficiência de ferro, caracterizada por longos períodos de balanço negativo deste elemento químico, pode levar ao esgotamento das reservas do organismo, dificultando assim a produção de hemácias, ocorrendo então a anemia ferropriva. Neste sentido, a definição de três estágios da deficiência no organismo é reconhecida. A deficiência de ferro pré-latente ou a depleção de ferro, refere-se à redução nas reservas (ferritina sérica) sem redução dos níveis de ferro sérico. A deficiência latente de ferro ocorre quando são exauridas as reservas de ferro, mas o nível de hemoglobina permanece acima do limite inferior do normal. Tal estágio caracterizase por algumas alterações bioquímicas no metabolismo de ferro, principalmente a redução da saturação da transferrina, assim como um aumento na capacidade total de ligação de ferro - CTLF. A anemia ferropriva ocorre quando a concentração de hemoglobina no sangue encontra-se abaixo do limite inferior do normal, ocorrendo também produção de eritrócitos microcíticos ${ }^{1,2}$. A Organização Mundial de Saúde estabeleceu como limite a concentração de $11 \mathrm{mg} / \mathrm{dL}$ de hemoglobina para menores de cinco anos ${ }^{11}$. Entretanto, este valor vem sendo questionado nos últimos anos ${ }^{12}$.

\section{Anemia Ferropriva}

A anemia ferropriva representa a deficiência nutricional de maior ocorrência em todo o mundo. Porém, apesar de sua significante prevalência em países desenvolvidos, atinge, essencialmente, expressivos contingentes da população dos países em desenvolvimento. Nestes países, metade dos préescolares são anêmicos, comparados a 7\% nos países desenvolvidos ${ }^{13,14}$.

De acordo com Roodenburg ${ }^{15}$, a anemia por deficiência de ferro apresenta prevalência global de 51\%. A Ásia, onde $60 \%$ das mulheres em idade reprodutiva e $40-50 \%$ dos pré-escolares e crianças são anêmicos, é responsável por três quartos do total de acometidos mundialmente ${ }^{14}$. Segundo estimativa realizada pela Organização Panamericana de Saúde (OPAS), o Peru representa o país de maior prevalência de anemia da América Latina, seguido do Caribe (57\%) e Brasil, onde 35\% das crianças, com idade entre 1 e 4 anos, encontram-se anêmicas ${ }^{16}$. Freire ${ }^{17}$ descreve que no continente americano aproximadamente 94 milhões de pessoas apresentam anemia ferropriva.

No Brasil, a proporção de anemia em crianças menores de 2 anos situa-se entre 50 a 83,5\% ${ }^{18}$. Estudos apontam elevada prevalência de anemia principalmente em crianças menores de 5 anos, sendo a faixa etária de 6 a 23 meses a de maior risco para o desenvolvimento desta doença ${ }^{16,18,19,20,21}$.

Diferenças na definição e no diagnóstico de anemia, assim como na metodologia adotada nos vários trabalhos científicos, devem ser criteriosamente consideradas para a comparação de resultados ${ }^{22}$.

\section{Manifestações Clínicas}

A anemia ferropriva, do mesmo modo que as demais anemias, não é uma doença, mas um sinal de doença. Aspectos clínicos podem incluir manifestações do processo de doença subjacente, assim como do estado de deficiência. O início da 
anemia ferropriva é quase invariavelmente insidioso, sendo gradual a progressão dos sintomas ${ }^{1}$.

A anemia por deficiência de ferro ou, em muitos casos, apenas a deficiência do mineral podem ocasionar fadiga, prejuízo no crescimento e no desempenho muscular, sendo que o tempo total de exercício, a carga máxima de trabalho, a taxa cardíaca e os níveis de lactato sérico, após exercício, são todos afetados adversamente em proporção ao grau de anemia, acarretando prejuízos no desenvolvimento neurológico e desempenho escolar, além de distúrbios comportamentais como irritabilidade, pouca atenção, falta de interesse ao seu redor e dificuldade no aprendizado, prejuízo na capacidade de manter a temperatura corporal na exposição ao frio, alterações no crânio, em crianças com anemia ferropriva de longa duração, como espaços diplóicos aumentados, tábuas externas afinadas, além de anormalidades nos ossos longos ${ }^{1}$.

De acordo com estudos revisados por Allen $^{23}$, existe uma associação negativa entre anemia e a duração da gestação e o baixo peso ao nascer. Rasmussen ${ }^{24}$ encontrou forte associação entre anemia grave $(\mathrm{Hb}<4,7 \mathrm{~g} / \mathrm{dL})$ e mortalidade materna. Brabin et al. ${ }^{25}$, após revisarem extensamente alguns estudos, observaram dados escassos em relação à mortalidade infantil e à deficiência de ferro em áreas não endêmicas de malária. Por outro lado, alguns estudos sugerem que a mortalidade, devido à anemia severa da malária, atinge maior número de indivíduos que a anemia decorrente da deficiência de ferro.

A deficiência de ferro e a anemia ferropriva podem prejudicar o desenvolvimento comportamental e cognitivo de crianças ${ }^{26}$. Entretanto, alguns autores não reconhecem a existência de evidências claras. Existem indicações consideráveis que a anemia está associada a um grande número de desvantagens socioeconômicas e biomédicas, tais como baixo status socioeconômico, falta de cuidados, atenção e estímulo em casa, baixa escolaridade materna, ausência paterna, baixo peso ao nascer, desnutrição, entre outros, que podem, por si só, prejudicar o desenvolvimento infantil ${ }^{27}$.

As evidências apresentadas por Haas \& Brownlie IV ${ }^{28}$, após revisarem 29 artigos, são muito claras quanto à substancial redução da capacidade de trabalho aeróbico na anemia, por deficiência de ferro, grave e moderada. Isto pode significar graves consequências econômicas, principalmente para países em desenvolvimento, que apresentam uma expressiva proporção de sua produção econômica baseada em mão-de-obra e trabalho físico ${ }^{13}$.

Alguns estudos dos efeitos da deficiência de ferro sobre a imunidade sugerem que indivíduos deficientes em ferro são mais propensos à infecção e mostram que a suplementação com ferro resulta na menor ocorrência de infecções respiratórias e gastrintestinais em crianças ${ }^{29,30}$. Embora faltem informações clínicas definitivas, uma vez que alguns estudos apresentam falhas de delineamento, um ponto está claro: a falta de ferro pode resultar no defeito na imunidade mediada por célula, devido à diminuição de células T circulantes e no prejuízo da morte bacteriana pelos neutrófilos ${ }^{31}$.

\section{Diagnóstico Laboratorial}

A carência de ferro ocorre no organismo de maneira gradual e progressiva. Neste sentido, diversos parâmetros hematológicos e bioquímicos que refletem os três estágios da deficiência podem ser usados, isoladamente ou associados, no diagnóstico do estado nutricional de ferro em indivíduos ou populações ${ }^{32}$.

O diagnóstico do primeiro estágio da deficiência de ferro, caracterizado pela diminuição dos estoques de ferro no organismo, é realizado por meio de dosagem de ferritina sérica ${ }^{10}$. A dosagem da hemossiderina na medula óssea pode também ser adotada como indicativo de depleção. Entretanto, por ser um método invasivo, não é recomendado para triagem.

O segundo estágio da deficiência de ferro corresponde à diminuição do ferro de transporte. Este estágio caracteriza-se pela diminuição do ferro sérico e um aumento da capacidade de ligação do ferro, sendo que tais mudanças resultam na diminuição da saturação da transferrina ${ }^{10}$. O ferro sérico corresponde a um parâmetro bastante utilizado, apesar de muito instável, pois pode estar alterado na presença de processos infecciosos, 
podendo diminuir em poucas horas após o desencadeamento da infecção. A capacidade total de ligação do ferro (CTLF), utilizada para avaliar o ferro circulante, aumenta na deficiência deste mineral, mas diminui na inflamação. Porém, deve ser avaliada criteriosamente, pois pode apresentar-se normal quando ambas coexistem, deficiência de ferro e inflamação. A saturação da transferrina, que corresponde à relação entre o ferro sérico e a CTLF, costuma ser utilizada, pois o ferro sérico e a CTLF isolados apresentam baixa especificidade e sensibilidade. Entretanto, este índice também se altera na presença de infecção. Contudo, representa um importante valor no diagnóstico diferencial da talassemia e da anemia ferropriva, uma vez que está invariavelmente elevado na talassemia ${ }^{33}$. Outro parâmetro para avaliação de ferro disponível aos tecidos é a protoporfirina eritrocitária livre (PEL). Recentemente, a utilização da medida de receptores de transferrina tem sido proposta como parâmetro de detecção de deficiência de ferro ${ }^{32}$.

O terceiro estágio ocorre quando a quantidade de ferro está suficientemente restrita para a produção de hemoglobina, apresentando células hipocrômicas e microcíticas. O volume corpuscular médio (VCM), que avalia o tamanho médio dos eritrócitos; a amplitude de variação do tamanho dos eritrócitos ou red distribution width (RDW), que avalia a variabilidade no tamanho dos eritrócitos; a hemoglobina corpuscular média $(\mathrm{HCM})$ e a concentração de hemoglobina corpuscular média (CHCM), que avaliam a concentração de hemoglobina no eritrócito, correspondem aos índices hematimétricos mais utilizados neste estágio ${ }^{32}$, além da hemoglobina, que corresponde ao parâmetro universalmente utilizado para diagnosticar anemia. Entretanto, a hemoglobina não possui boa especificidade e sensibilidade, pois pode estar alterada em condições de infecção e inflamação, hemorragia, hemoglobinopatias, desnutrição protéico-calórica, deficiência de folato e/ou vitamina B12, uso de medicamentos, desidratação, gestação e tabagismo ${ }^{32,33,34}$. Segundo Cook et al..$^{33}$, o valor de VCM abaixo de $80 \mathrm{fL}$ (fentolitros) parece ser um indicador confiável da redução da síntese de hemoglobina. Mas, por considerar o tamanho médio das células vermelhas, não fornece uma idéia da variabilidade do tamanho destas células no sangue periférico. Deste modo, deve ser utilizado em conjunto com o RDW, o qual tem-se revelado eficiente na diferenciação da deficiência de ferro, da talassemia menor e das infecções crônicas. De acordo com Beaton et al. ${ }^{35}$, o hematócrito fornece informações similares à concentração de hemoglobina, podendo ser usado conjuntamente no diagnóstico de anemia.

Segundo Paiva et al. ${ }^{32}$, não existe um parâmetro de excelência para o diagnóstico do estado nutricional de ferro e sua escolha deve considerar as características inerentes ao indivíduo ou grupo populacional, a prevalência e gravidade da deficiência de ferro, a incidência de doenças inflamatórias e infecciosas e a freqüência de doenças hematológicas, o volume de amostra necessário, o custo e a complexidade da metodologia utilizada e a suscetibilidade a erros laboratoriais.

\section{Anemia de Doença Crônica}

A anemia de doença crônica ${ }^{3}$ é definida pela presença de uma doença crônica, infecciosa (fúngicas, bacterianas e virais), inflamatória ou neoplásica, anemia e hipoferremia, apesar de abundante quantidade de ferro nos macrófagos. Sua gravidade está muitas vezes relacionada ao grau de infecção ${ }^{10,30}$.

A anemia é normocítica e normocrômica ou hipocrômica, podendo ainda ocorrer hipocromia e microcitose em 20 a 30\% dos pacientes com doença crônica. Porém, a microcitose, quando ocorre, não é tão acentuada como na anemia ferropriva, sendo que o volume corpuscular médio - VCM - raras vezes se encontra abaixo de $72 \mathrm{fL}^{2}$. Anisocitose e poiquilocitose podem também ocorrer, mas tais alterações são menos proeminentes do que na anemia por deficiência de ferro ${ }^{30}$.

Na patogênese da anemia de doença crônica atuam pelo menos três mecanismos: alterações na eritropoese, diminuição da sobrevida das hemácias e resposta inadequada da medula à hemólise ${ }^{36,37 .}$

Quanto às alterações na eritropoese, a ocorrência de um bloqueio na liberação do ferro dos macrófagos, levando à diminuição do ferro disponível para a síntese da hemoglobina, parece ser 
o principal fator relacionado a estas alterações ${ }^{36}$. Normalmente, os macrófagos adquirem ferro por fagocitose de hemácias fracas, das quais a hemoglobina é retirada e catabolizada. O ferro liberado neste processo retorna ao plasma por meio de duas vias diferentes: uma rápida, associada com a liberação quase imediata do ferro retirado da hemoglobina, e uma mais lenta, proveniente de ferro incorporado nos depósitos de armazenamento das células. $\mathrm{Na}$ anemia de doença crônica ocorre um bloqueio da via mais rápida, sendo que a quantidade de ferro armazenado aumenta e este é liberado pela via mais lenta ${ }^{38}$. O papel da transferrina, assim como da lactoferrina, é fundamental no processo que leva o organismo à condição de hipoferremia ${ }^{39}$. A lactoferrina, proteína semelhante à transferrina, é secretada pelos neutrófilos e liberada durante estimulação pela interleucina-1 (IL-1). Esta proteína liga-se ao ferro com mais avidez que a transferrina, principalmente em $\mathrm{pH}$ baixo, não transporta ferro para as células eritropoéticas e é captada rapidamente pelos receptores específicos da membrana sobre os macrófagos ${ }^{38}$. A apoferritina, sintetizada em resposta ao aumento da concentração intracelular de ferro, quando em excesso, liga-se a uma quantidade maior que o usual de ferro que penetra na célula, desviando-o da via rápida para a via lenta de liberação, aumentando assim a quantidade de ferro no interior dos macrófagos 3,40 .

$\mathrm{Na}$ anemia de doença crônica ocorre encurtamento leve a moderado da sobrevida das hemácias (cerca de 80 dias, ao invés de 120 dias normais) ${ }^{36}$. Este fenômeno é atribuído ao estado de hiperatividade do sistema mononuclear fagocitário, desencadeado por processo infeccioso, inflamatório ou neoplásico, levando à remoção precoce dos eritrócitos circulantes. Outros fatores, tais como a febre, a liberação de hemolisinas e a liberação de toxinas bacterianas, podem levar ao aumento da hemólise ${ }^{3}$.

A resposta inadequada da medula à hemólise leve deve-se a possíveis defeitos na eritropoese, como a diminuição inapropriada da secreção de eritropoetina ou a resposta reduzida da medula óssea à eritropoetina e eritropoese, limitada pela menor oferta de ferro ${ }^{2,37}$. A medula óssea normalmente é capaz de aumentar de 6 a 8 vezes a taxa de produção de hemácias. Mas, sua capacidade de produção está prejudicada na anemia de doença crônica. Isto ocorre em conseqüência da ação de citocinas que atuam como supressoras da eritropoese $e^{41}$.

\section{Imunidade e Infecção}

É controversa a relação entre o ferro e a imunidade. Enquanto alguns autores afirmam que a deficiência de ferro predispõem às infecções, outros sugerem que o excesso de ferro pode aumentar o risco de infecções e também sua gravidade, pois os microrganismos, assim como os animais, necessitam de ferro para o desenvolvimento das funções vitais como síntese de DNA e transporte de elétrons ${ }^{42,43}$.

Segundo Kent et al. ${ }^{39}$, a anemia de doença crônica representa uma defesa do organismo contra a proliferação de microrganismos e de células neoplásicas e pode estar envolvida, juntamente com a febre, como estratégia complementar que o organismo emprega para se proteger da doença. Após a invasão bacteriana, ocorre a resposta inflamatória com a liberação de alguns mediadores, como as citocinas: interleucina-1 (IL-1), interleucina-6 (IL-6), fator de necrose tumoral alfa (FNT $\alpha)$ e interferon gama (INF $\gamma)^{38,44}$. Tais mediadores atuam inibindo a eritropoese, diminuindo a disponibilidade do ferro para as bactérias, aumentando a síntese de ferritina, suprimindo a assimilação do ferro intestinal, aumentando a retenção de ferro pelos macrófagos, induzindo a retirada de ferro dos locais de invasão bacteriana pela apolactoferrina e provocando a síntese de anticorpos contra o sistema de captação de ferro pelas bactérias ${ }^{41,44}$.

O baixo nível de ferro plasmático inibe o crescimento bacteriano. Desta forma, as anormalidades no metabolismo de ferro podem representar um mecanismo evoluído de defesa do hospedeiro contra a invasão bacteriana ${ }^{3}$. Tal fenômeno é denominado imunidade nutricional.

\section{Considerações Finais}

Durante várias décadas, esforços substanciais têm sido realizados mundialmente, para implementar programas que reduzam a anemia e a deficiência de ferro. Porém, o sucesso destes programas apresenta 
limitações, que não são atribuídas à falta de conhecimento sobre a prevalência, causas e conseqüências da deficiência de ferro, mas a intervenções pouco efetivas. Segundo Colli \& Szarfarc ${ }^{45}$, muitos estudos de intervenção desenvolvidos no Brasil apresentam respostas positivas ao aumento da ingestão de ferro. Estes estudos destacam a suplementação profilática como a forma mais econômica de intervenção. No entanto, sua eficácia é reduzida pela baixa aceitação do suplemento, diminuindo assim a adesão ao tratamento. Em muitos países desenvolvidos, progressos significativos na redução da deficiência de ferro têm ocorrido, sendo que uma série de fatores associados ao desenvolvimento econômico e à implementação de políticas públicas específicas, como fortificação, suplementação e diversificação da dieta, têm contribuído para o aumento da ingestão dietética de ferro ${ }^{46,47,48}$.

Por outro lado, alguns autores acreditam que os marcadores utilizados, particularmente seus limites de corte, devem ser revistos, pois podem estar superestimando a anemia ferropriva e a deficiência de ferro ${ }^{49}$. O correto diagnóstico da anemia por deficiência de ferro é de fundamental importância para se evitar e reduzir os riscos à saúde. Nas anemias de doença crônica, é importante ter cautela ao se utilizar o ferro, pois este pode representar um papel crítico, podendo estar biodisponível para os organismos patogênicos, os quais se utilizarão deste para suas próprias funções, agravando assim as infecções ${ }^{50}$. Nos casos em que tanto a anemia ferropriva, como a anemia de doença crônica ocorrem simultaneamente, o tratamento da anemia por deficiência de ferro deve ser iniciado após o período de infecção.

\section{Referências Bibliográficas}

1. Lee JR. Microcitose e as anemias associadas com síntese prejudicada da hemoglobina. In: Lee GR et al. Wintrobe - Hematologia Clínica. São Paulo: Mir; 1998a. p.884-919.

2. Kushner JP. Anemias hipocrômicas. In: Wyngaarden JB, Smith LH, Bennett JC. Cecil Tratado de Medicina Interna. Rio de Janeiro: Guanabara Koogan 1993; p.858-865.
3. Cançado RD \& Chiattone CS. Anemia de doença crônica. Revista Brasileira de Hematologia e Hemoterapia 2002; 4: 127-136.

4. Carpenter CE \& Mahoney A. Contributions of heme and nonheme iron to human nutrition. Crit Rev Food Sc Nutr 1992; 31: 333-367.

5. Worwood M. Regulação do metabolismo do ferro. Anais Nestlé 1996; 52: 1-10.

6. Food and Nutrition Board. Dietary reference intakes for vitamin $\mathrm{A}$, vitamin $\mathrm{K}$, arsenic, boron, chromium, copper, iodine, iron, manganese, molybdenum, nickel, silicon, vanadium, and zinc. Washington: National Academy of Sciences; 2001.

7. CDC-Center For Disease Control And Prevention. Recommendation to prevent and control iron deficiency in the United States. Morbid and Mortality Weekly Reports 1998; 47: 1-29.

8. TBNF-The British Nutrition Foundation. Iron: nutritional and physiological significance. The Report of the British Nutrition Foundation's Task Force. London: Chapman \& Hall; 1995, 186p.

9. Wingard RL, Parker RA, Ismail N, Hakim RM. Efficacy of oral iron therapy in patients receiving recombinant human erythropoietin. Am J Kidney Diseases 1995; 25: 433-439.

10. Dallman PR, Yip R, Oski, F.A. Iron deficiency and related nutritional anemias. In: Oski, FA. Principles and Practices of Pediatrics. $2^{\text {th }}$ ed. Filadelphia: J.B.Lippincott Company; 1994. p.413450.

11. International Nutrition Anemia Consultative Group (INAGG) and World Health Organization (WHO) and United Nations Children's Fund (UNICEF). Guidelines for the use of iron supplements to prevent and treat iron deficiency anaemia. Washington DC: International Life Sciences Institute; 1998.

12. Aggett, P.G.; Agostoni, C.; Axelsson, I.; et al. Iron metabolism and needs in early childhood: do we know enough? A commentary by ESPGHAN Committee on Nutrition. J Pediatr Gastroenterol 
Nutr 2002; 34: 337-345.

13. Yip R. Iron deficiency: contemporary scientific issues and international programmatic approaches. J Nutr 1994; 124: 1479S-1490S.

14. Hunt J.M. Reversing productivity losses from iron deficiency: the economic case. J Nutr 2002; 132: 794S-801S.

15. Roodenburg AJC. Iron supplementation during pregnancy. Eur J Obstetr Gynec Reprod Biol 1995; 61: 65-71.

16. Neuman NA, Tanaka OT, Szarfarc SC. Et al. Prevalência e fatores de risco para anemia no sul do Brasil. Rev Saúde Pública 2000; 34: 56-63.

17. Freire, W.B. La anemia por deficiencia de hierro: estrategias de la OPS/OMS para combatirla. Salud Publica Mex 1998; 40: 199-205.

18. Torres MAA, Sato K, Lobo NF, Queiroz SS. Efeito do uso de leite fortificado com ferro e vitamina C sobre os níveis de hemoglobina e condição nutricional de crianças menores de 2 anos. Rev Saúde Pública 1995; 29: 301-307.

19. Torres MAA, Lobo NF, Sato K, Queiroz SS. Fortificação de leite fluido na prevenção e tratamento da anemia carencial ferropriva em crianças menores de 4 anos. Rev Saúde Pública 1996; 30: 350-357.

20. Szarfarc S \& Souza SB. Prevalence and risk factors in iron deficiency and anemia. Arch Latinoam Nutricion 1997; 47: 35-38.

21. Oliveira RS et al. Magnitude, distribuição espacial e tendência da anemia em pré-escolares da Paraíba. Rev Saúde Pública 2002; 36: 26-32.

22. Hay, G.; Sandstad, B.; Whitelaw, A. \& BorchIohnsen, B. Iron status in a group of Norwegian children aged 6-24 months. Acta Paediatr 2004; 93: 592-598.

23. Allen LH. Biological mechanisms that might underlie iron's effects on fetal growth and preterm birth. J Nutr 2001; 131: 581S-589S.
24. Rasmussen KM. Is there a casual relationship between iron deficiency or iron-deficiency anemia and weight at birth, length of gestation and perinatal mortality? J Nutr 2001; 131: 590S-603S.

25. Brabin BJ, Hakimi M, Pelletier D. An analysis of anemia and pregnancy-related maternal mortality. J Nutr 2001; 131: 604S-615S.

26. Akman, M; Cebeci, D.; Okur, V. et al. The effects of iron deficiency on infants' developmental test performance. Acta Paediatr 2004; 93: 1391-1396.

27. Granthan-Mcgregor S \& Ani C. A review of studies on effect of iron deficiency on cognitive development in children. J Nutr 2001; 131: 649S$668 \mathrm{~S}$.

28. Hass JH \& Brownlie IVT. Iron deficiency and reduced work capacity: a critical review of the research to determine a causal relationship. J Nutr 2001; 131: 676S-690S.

29. Thibault $\mathrm{H}$ et al. The immune response in irondeficient young children: effect of iron supplementation on cell-mediated immunity. Eur J Pediatr 1993; 152: 120-124.

30. Lee JR. Deficiência de ferro e anemia ferropriva. In: Lee GR et al. Wintrobe - Hematologia Clínica. São Paulo: Mir; 1998b. p.884-919.

31. Dallman PR. Iron deficiency and the immune response. Am J Clin Nutr 1987; 34: 329-334.

32. Paiva AA, Rondó PHC, Guerra-Shinohara EM. Parâmetros para avaliação do estado nutricional de ferro. Rev Saúde Pública 2000; 34: 421-426.

33. Cook JD, Baynes RD, Skikne BS. Iron deficiency and the measurement of iron status. Nutr Res Rev 1992; 5: 189-202.

34. Beard JL, Dawson H, Piñero DJ. Iron metabolism: a comprehensive review. Nutr Rev 1996; 54: 295-317.

35. Beaton GH, Corey PN, Steele C. Conceptual and methodological issues regarding the epidemiology of iron deficiency and their implications for studies 
of functional consequences of iron deficiency. Am J Clin Nutr 1989; 50: 575-588.

36. Alvin RC, Azevedo WM, Silva CM. Manifestações hematológicas das doenças infecciosas na infância: In: Tonelli E. Doenças infecciosas na infância. Rio de Janeiro: Medsi; 1987. p.1274-1288.

37. Means RT \& Krantz SB. Progress in understanding the pathogenesis of the anemia of chronic disease. Blood 1992; 80: 1639-1647.

38. Jurado RL. Iron, infections, and anemia of inflammation. Clin Infect Disease 1997; 25: 888-895.

39. Kent S, Weinberg ED, Stuart-Macadam P. The etiology of the anemia of chronic disease and infection. J Clin Epidemiol 1994; 47: 23-33.

40. Konijn AM, Carmel N, Levy R, Hershko C. Ferritin synthesis in inflammation. II. Mechanism of increased ferritin synthesis. Br J Haematol 1981; 49: 361-370.

41. Katevas P et al. Peripheral blood mononuclear cells from patients with rheumatoid arthritis suppress erythropoiesis in vitro via the production of tumor necrosis factor alpha. Eur J Haem 1994; 53: 26-30.

42. Power HM, Heese HV, Beatty DW, Hughes J, Dempster WS. Iron fortification of infant milk formula: the effect on iron status and immune function. Ann Trop Pediatr 1991; 11: 57-66.

43. Souza RL \& Succi RCM. Oligoelementos e Infecção. Pediatria Moderna 1996; 31: 660-667.

44. Weinberg ED. Iron depletion: a defense against intracellular infection and neoplasia. Life Sciences 1992; 50: 1289-1297.
45. Colli C, Szarfarc SC. Reflexões sobre a deficiência de ferro no Brasil. Cadernos de Debates. 2003; 10:7788.

46. Allen LH. Iron supplements: scientific issues concerning efficacy and implications for research and programs. J Nutr 2002; 132: 813S-819S.

47. Hurrel, R.F. Fortification: overcoming technical and practical barriers. J Nutr 2002; 132: 806S-812S.

48. Ramakrishnan U \& Yip R. Experiences and challenges in industrialized countries: control of iron deficiency in industrialized countries. J Nutr 2002; 132: 820S-824S.

49. Hernell, O. \& Lönnerdal, B. Is iron deficiency in infants and young children common in Scandinavia and is there a need for enforced primary prevention? Acta Paediatr 2004; 93: 1024-1026.

50. Boelaert JR. Iron and infection. Acta Clinical Bélgica 1996; 51: 213-221.

\section{Autores}

Miriam Corrêa de Carvalho - Pesquisadora do Núcleo de Estudos e Pesquisas em Alimentação - NEPA (UNICAMP)

Correspondência: Avenida Albert Einstein, 291 - Cidade Universitária - Campinas-SP, CEP. 13.083-852, E-mail: micc@unicamp.br

Emílio Carlos Elias Baracat - Professor Assistente Doutor do Departamento de Pediatria da Faculdade de Ciências Médicas (UNICAMP)

Valdemiro Carlos Sgarbieri - Professor Titular e Pesquisador Convidado do Departamento de Alimentos e Nutrição da Faculdade de Engenharia de Alimentos (UNICAMP) 